\title{
Applications of self-assembling peptide scaffolds in regenerative medicine: the way to the clinic
}

\author{
Ranjithkumar Ravichandran, May Griffith and Jaywant Phopase
}

\section{Linköping University Post Print}

\section{Tweet}

N.B.: When citing this work, cite the original article.

Original Publication:

Ranjithkumar Ravichandran, May Griffith and Jaywant Phopase, Applications of selfassembling peptide scaffolds in regenerative medicine: the way to the clinic, 2014, Journal of materials chemistry. $\mathrm{B},(2), 48,8466-8478$.

http://dx.doi.org/10.1039/c4tb01095g

Copyright: Royal Society of Chemistry

http://www.rsc.org/

Postprint available at: Linköping University Electronic Press

http://urn.kb.se/resolve?urn=urn:nbn:se:liu:diva-113073 


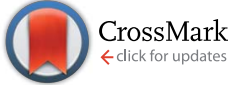

Cite this: J. Mater. Chem. B, 2014, 2 , 8466

Received 5th July 2014

Accepted 8th October 2014

DOI: $10.1039 / c 4 t b 01095 \mathrm{~g}$

www.rsc.org/MaterialsB

\section{Applications of self-assembling peptide scaffolds in regenerative medicine: the way to the clinic}

\author{
Ranjithkumar Ravichandran, ${ }^{a}$ May Griffith ${ }^{\mathrm{b}}$ and Jaywant Phopase*a \\ Peptides that self-assemble into well-defined nanofibrous networks provide a prominent alternative to \\ traditional biomaterials for fabricating scaffolds for use in regenerative medicine and other biomedical \\ applications. Such scaffolds can be generated by decorating a peptide backbone with other bioactives \\ such as cell specific adhesion peptides, growth factors and enzyme cleavable sequences. They can be \\ designed to mimic the three-dimensional (3D) structural features of native ECM and can therefore also \\ provide insight into the ECM-cell interactions needed for development of scaffolds that can serve as \\ regeneration templates for specific target tissues or organs. This review highlights the potential \\ application of self-assembling peptides in regenerative medicine.
}

\section{Introduction}

Biomaterials are being used to enhance or enable stem/ progenitor cell-based therapies in Regenerative Medicine. Both synthetic and natural biomaterials are used to deliver drugs, bioactives or stem cells, or as scaffolds to enable the regeneration of failing and failed organs. ${ }^{1-3}$ Despite the research success to date, many implants in clinical use are still sub-optimal. For example, many "regulatory approved" plastics that are deemed biocompatible were not initially intended for use in the human body, and therefore, suffer from immune compatibility issues

${ }^{a}$ Integrative Regenerative Medicine (IGEN) Centre and Division of Molecular Physics, Department of Physics, Chemistry and Biology(IFM), Linköping University, S-58183 Linköping, Sweden. E-mail: jayph@ifm.liu.se; Tel: +4613282713

${ }^{b}$ Integrative Regenerative Medicine (IGEN) Centre and Dept. of Clinical and Experimental Medicine, Linköping University, S-58185 Linköping, Sweden and/or lack of a bio-interactive interface with the host's tissues..$^{2,3}$

The extracellular matrix (ECM) macromolecules of the human body that have directed the initial development of organs during embryogenesis also help direct its repair and regeneration. ${ }^{\mathbf{4} 5}$ Within the body, the various ECM components self-assemble to form the natural scaffolding that provides mechanical support to the various organs. More importantly, the ECM components also modulate the behavior of the cells that they contact by sequestration of bioactive growth factors to guide tissue formation, as well as providing cues at the nano levels, for example, through the topology or nano architecture. ${ }^{\mathbf{4 , 5}}$ Therefore, the fundamental challenge in constructing artificial scaffolds is to predictably manipulate the fabrication process at nano level in order to build-in the properties needed to mimic the complex 3D structure of the native ECM of the target organ of interest.

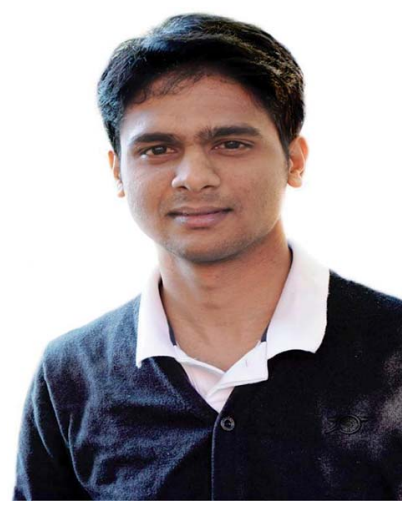

Mr Ranjithkumar Ravichandran received his Masters in Medical Nanotechnology from Sastra University, India. His thesis project was on the use of mesoporous silica fibers as regenerative templates for promoting bone regeneration. In 2013 he started his Ph.D. studies with Dr Jaywant Phopase at Linköping University, where he is developing multi-component hydrogels as biomimetic building blocks for tissue engineering and regenerative medicine.

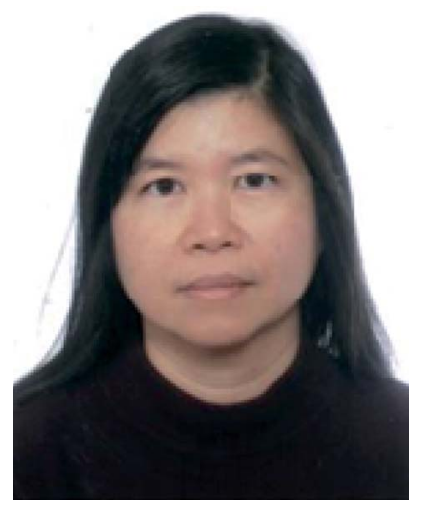

Dr May Griffith is Professor of Regenerative Medicine and Scientific Director of the Integrative Regenerative Medicine Centre (IGEN) at Linköping University, Sweden. Her research is in the area of regenerative medicine, specifically tissue engineering. She has been developing collagen-based materials for regeneration of the cornea and has demonstrated successful, stable corneal regeneration in a phase I clinical trial. She also has ongoing projects in cardiovascular, nerve and skin repair. 


\subsection{Self-assembling biomolecules}

Self-assembling supramolecular materials have to be constructed from the nanoscale level upwards to allow for ordering into highly organized structures at the micro- and then macro scale to provide tailor-made biomaterials for a range of biomedical applications. ${ }^{6-9}$ Within the human body, building blocks at the molecular level such as DNA, RNA, phospholipids, amino acids can spontaneously associate with each other. Under thermodynamically favorable conditions, they associate to form well-defined complex structures that result from a balance amongst numerous non-covalent weak interactions such as hydrogen bonds, electrostatic interactions, hydrophobic interactions, van der Waals forces and aromatic $\pi-\pi$ stacking: ${ }^{6,10-12}$

These self-assembled blocks have found applications in numerous fields ranging from electronics to nanomedicine. ${ }^{\mathbf{1 0 - 1 2}}$ The self-assembling peptide systems, however, are most prominent in these diverse technological applications, due to the advantages they offer, from their ease in design and synthesis to industrial level scaling-up. ${ }^{\mathbf{1 3}}$ To promote organ regeneration, it is necessary for biomaterial implants or scaffolds to mimic the in vivo $3 \mathrm{D}$ microenvironment to allow seamless integration with the host tissue to affect repair and regeneration of damaged tissues. In this context, peptide scaffolds have advantages over other polymeric biomaterials because their natural nanofibrous morphology mimics the in vivo ECM and they have high biocompatibility. In addition, their biodegradation products, which are amino acids, are in general, non-toxic to the surrounding cells and tissues. ${ }^{\mathbf{1 4}}$

\subsection{Self-assembling peptides (SAPs)}

Self-assembling peptides fall into two categories, namely natural and non-natural systems. In the natural system, the

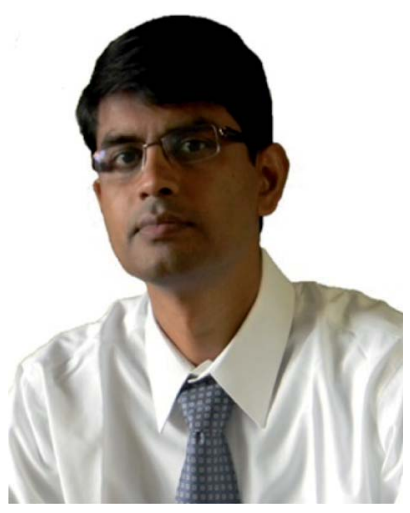

Dr Jaywant Phopase is an Assistant Professor at the Integrative Regenerative Medicine Centre \& Department of Physics, Chemistry and Biology, Linköping University. He obtained his Ph.D. in 2008 from Technische Universität Wien (TU Wien Austria) followed by an Irish Research Council (IRCSET) Postdoctoral Research Fellowship to support his research at the National Institute for Cellular Biotechnology and School of Chemical Sciences, at Dublin City University in Ireland. JP's research focuses on synthesis and application of functional building blocks inspired by natural materials that can be modularly assembled into nanofibrous hydrogels. In particular, his goal is to create a series of multi-component $3 D$ scaffolds, with varying biological and physical properties for regenerative medicine and biomedical application JP has received a Swedish Research Council Young Investigator Award in support of his research. basic conformational unit of the peptide acts as building block providing the possibility for a range of peptide arrangements by changing the respective amino acids. ${ }^{6-8,15}$ In the non-natural system, the amino acids are covalently linked to other molecules to form amphiphile-like structures or $\pi-\pi$ interactions between the aromatic amino acids. ${ }^{9,15}$ Peptides therefore offer a unique platform to design self-assembled materials with controllable structural features at the nanoscale due to the flexibility and versatility afforded by amino acid sequences that in turn lead to numerous possible secondary, tertiary and quaternary structures through folding and hydrogen bonding. ${ }^{\mathbf{1 4 , 1 5}}$ By introduction of appropriate functionalities of amino acids into the peptide backbone, different structures such as vesicles, micelles, rods, ribbons, tapes and nanofibers can be obtained under the appropriate physicochemical conditions. ${ }^{14,15}$ They can be readily synthesized by standard peptide synthesis protocols and their characterizations, structural folding, stability have already been extensively investigated before. ${ }^{\mathbf{1 6 , 1 7}}$ Although there are many peptides that are employed in a range of biological applications, in this minireview, we only highlight the self-complementary ionic peptides that forms $\beta$-sheets and peptide amphiphiles, and particularly those that are being evaluated in vivo or used clinically in tissue engineering and regenerative medicine applications.

\section{Ionically complementary peptides}

Ionically complementary peptides were first identified over 20 years ago (1993) by Zhang and colleagues. This first peptide, EAK16-II, which was found in the baker's yeast protein, zuotin, has been referred to as "peptide Lego". ${ }^{6-8,10-12}$ This is because like Lego bricks, which have pegs and holes that allow them to be assembled into larger structures, EAK16-II and other similar peptides can form stable $\beta$-sheets with two distinct surfaces hydrophilic-pegs and hydrophobic-holes. This allows formation of complementary ionic bonds at the hydrophilic surface in aqueous solutions Fig. 1A..$^{6-8,10-12}$ These hydrophilic surfaces, depending upon the pattern of arrangements of alternating + and - charges of amino acids in the peptide backbone, have been grouped under different moduli. The orientation of charges in these peptide Lego macromolecules plays an important role in their self-assembly, and the reverse orientation of charges can result in entirely different molecules, yielding distinct molecular structures. One of the best known ionically complementary peptides, RADARADARADARADA (RADA16-I) has been commercialized as PuraMatrix. ${ }^{6-8,10-12}$ RADA16-I molecules readily undergo self-assembly in aqueous solutions to form $\beta$-sheet nanofibrous structures, which have found a range of diverse biomedical applications such as nanofibrous scaffolding for in vitro/in vivo tissue engineering and regenerative applications. These nanofibrous scaffolds are extremely hydrated (99\% water retention) and have the 3D ordered pore sizes of 5-200 $\mathrm{nm}$, closely mimicking the properties of native ECM for aiding in the regeneration of tissues. ${ }^{18,19}$ In addition, the nanopores of RADA16 scaffolds are close in size to that of small molecule drugs and other therapeutic moieties, 
A $+\quad-\quad+\quad+\quad+\quad+\quad-$

Ac-R-A-D-A-R-A-D-A-R-A-D-A-R-A-D-A-CONH

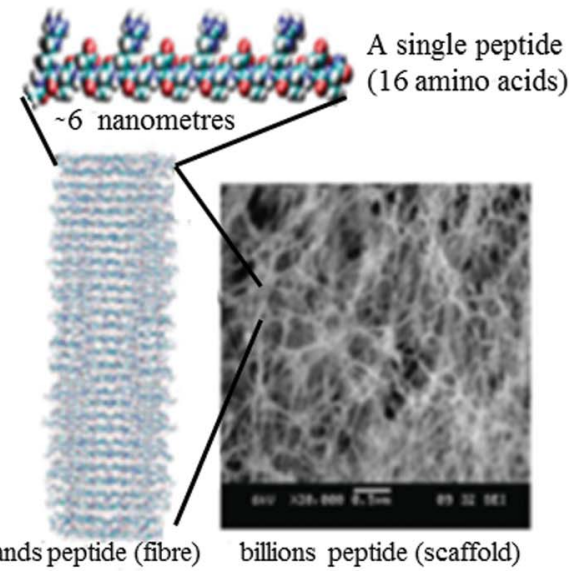

Thousands peptide (fibre) billions peptide (scaffold)

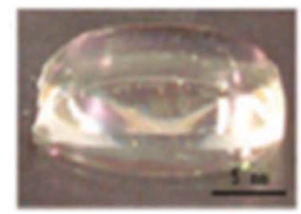

B

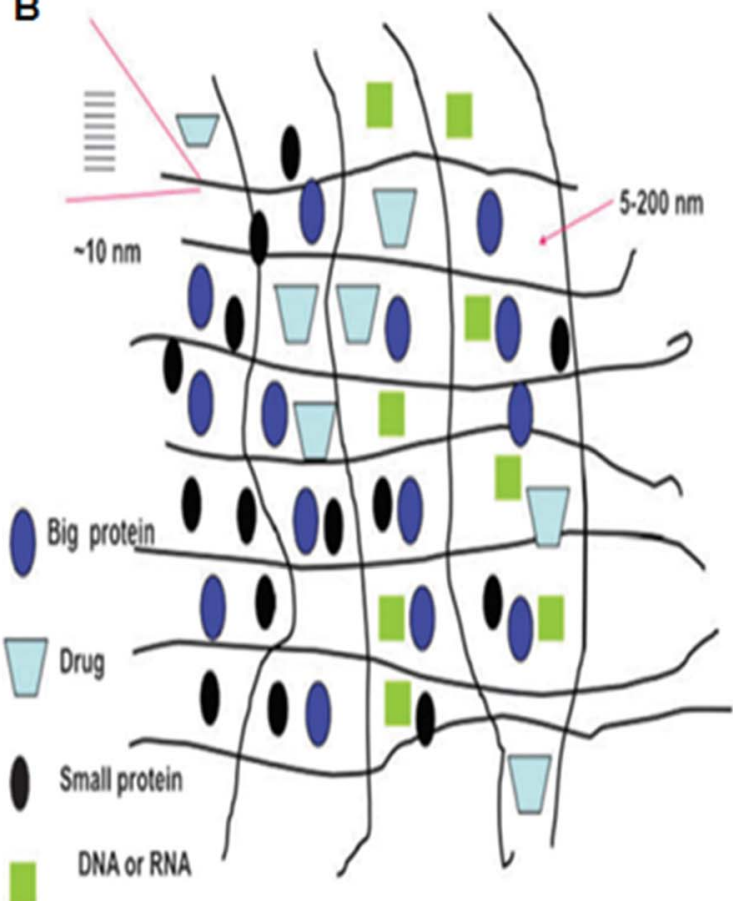

Fig. 1 (A) The "peptide Lego" structure of an ionic self-complementary peptide comprising of 16 amino acids, $\sim 5 \mathrm{~nm}$ in size with an alternating polar and nonpolar pattern that gives rise to a $\beta$-sheet structure. They undergo self-assembly to form nanofibers with the nonpolar residues inside (green), + (blue) and - (red) charged residues form complementary ionic interactions into hydrogel. (B) Schematic illustration, showing the release of biomolecules (drugs, growth factors etc.) from a peptide matrix. Figure adapted and reproduced with permission from Fig. 3 and 11 of ref. 17.

and therefore, are ideal for use as delivery vehicles for their sustained release (Fig. 1B)., ${ }^{7,17,19}$

Aggeli and co-workers also developed a class of fibrillating peptides $\mathrm{P}_{11}$, which adopts $\beta$-sheet conformations under appropriate physio-chemical conditions. ${ }^{18}$ In $\mathrm{P}_{11}$ peptides, several glutamine residues with alternating polar and aromatic residues were incorporated to promote the formation of $\beta$-sheet structures, driven by hydrogen bonding and interactions between the amino acid side chain components. The influence of several parameters such as $\mathrm{pH}$, monomer concentration and amino acid charge, induces the formation of hierarchical supramolecular structures from $\beta$-sheet monomers to tapes, ribbons and fibers. Above a critical concentration, the peptides further entangle into higher order viscoelastic networks to form hydrogels or organogels under aqueous or organic conditions respectively. Aggeli et al. further showed that $\mathrm{P}_{11}$ peptides were noncyotoxic to murine cells and did not elicited any immune response in mice. ${ }^{18} \mathrm{~A}$ major advantage of $\mathrm{P}_{11}$ peptides is that they are liquid prior to injection but will undergo stimuliresponsive self-assembly (depending on $\mathrm{pH}$, ionic-strength, addition of complementary counterpart) at the target site., ${ }^{9,18}$

Although ionically complementary self-assembling peptides (SAPs) are promising as scaffolds for tissue regeneration on their own, they are inert and do not exhibit any cellular interactions because these peptide sequences are not found within living systems. ${ }^{18}$ So, the second generation of SAPs developed now incorporate cell specific functional motifs

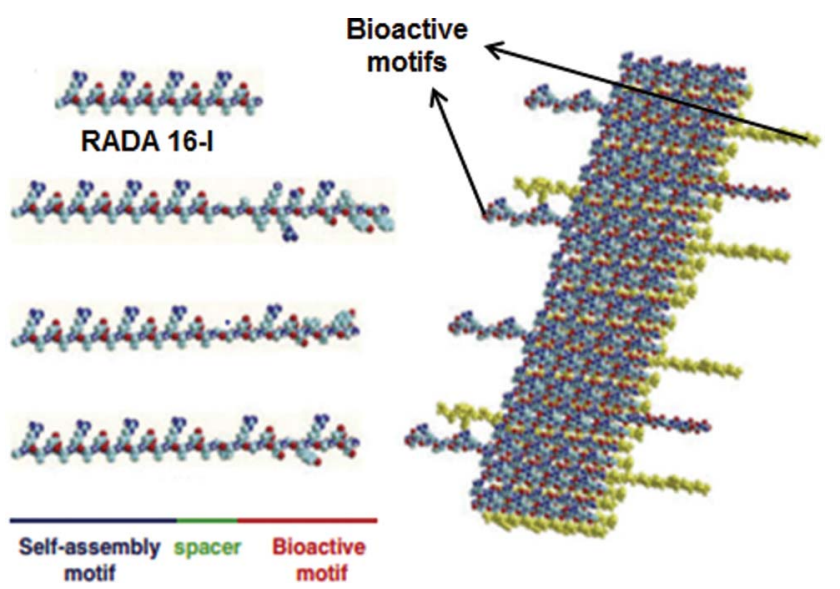

Fig. 2 Modification of RADA 16-I with bioactive functional domains to aid in multiple cell functions for tissue regeneration. The bioactive motifs were added to the C-termini during peptide synthesis, separated by a short spacer. Upon self-assembly, the motifs assembled themselves on the side of the matrix without hindering the nanofibrous morphology of native peptide matrix. Figure adapted and reproduced with permission from Fig. 6 of ref. 14; copyright 2012, Elsevier.

or bioactive ligands, growth factors, enzyme cleavable sequences or other bio-functionalization of the peptide backbone for desired cell specific applications (Fig. 2)..$^{7,13,14,17}$ In such SAPs, each and every constituent in the scaffold is defined and can be combined with multiple 
functionalities. ${ }^{7, \mathbf{1 3 , 1 4 , 1 7}}$ Desired functional and bioactive motifs can be incorporated into the peptide backbone via solid phase synthesis to achieve specific biological responses. ${ }^{\mathbf{1 3 , 1 4 , 1 8}}$

The addition of functional motifs to RADA16-I peptide scaffolds does not hinder the fibrous morphology of the scaffold as it self-assembles upon exposure to the solution leaving the added motifs on both sides of the scaffold..$^{13,14,17}$ This nanofiber scaffold along with functional motifs is completely different from a 2-D surface. Instead, the functionalized nanofibers are able to surround the cell body, mimicking a plausible 3-D microenvironment for specific tissue regeneration.

\subsection{Assembly into nanofibrous hydrogels}

Fig. 1A shows the hierarchical fashion of the self-assembling phenomenon. In the first step, monomers of SAPs spontaneously assemble into supramolecular nanostructures such as small fibrils in the aqueous solution. The assembled nanostructures then form higher ordered nanofibrous structures. Finally, the nanofibers make complex molecular networks by various physical interactions with each other to from fibrous hydrogels. ${ }^{20}$ The entanglement of peptide bases to form nanofibrous structures at physiological conditions renders SAPs as suitable building blocks for formulating bioactive hydrogel

Table 1 Examples of SAP used in vivo for tissue regeneration

\begin{tabular}{|c|c|c|c|}
\hline Year & Type of SAP & $\begin{array}{l}\text { Functional motif or } \\
\text { growth factors with SAP }\end{array}$ & In vivo tissue regeneration/ref. \\
\hline \multirow[t]{7}{*}{2014} & RADA16 & & $\begin{array}{l}\text { Employed clinically as sealant material to } \\
\text { reduce peritoneal effusion in pelvic surgery }\end{array}$ \\
\hline & RADA16 & & $\begin{array}{l}\text { Encapsulated with subATDPCs in PCLMA matrix to } \\
\text { promote regeneration in MI mice }\end{array}$ \\
\hline & PA & YIGSR \& RGD & Corneal stroma regeneration in rabbit models ${ }^{66}$ \\
\hline & $\mathrm{K}_{2}(\mathrm{QL})_{6} \mathrm{~K}_{2}(\mathrm{QL})_{6}$ & & $\begin{array}{l}\text { Transplanted with NPC to aid in forelimb functional recovery in } \\
\text { cervical spinal injury in mice }\end{array}$ \\
\hline & KLD-12 & & Encapsulated with BMSCs to prevent osteoarthritis progression in rats ${ }^{59}$ \\
\hline & PA & RGD & $\begin{array}{l}\text { Aligned PAs bridged sciatic nerve gap and reverted hind } \\
\text { limb sensory function in mice }{ }^{41}\end{array}$ \\
\hline & RADA16 & & $\begin{array}{l}\text { Enriched DBM/RADA16 promoted osteogenesis in mice and } \\
\text { repaired femur bone in goats }{ }^{59}\end{array}$ \\
\hline \multirow[t]{7}{*}{2013} & $\mathrm{P}_{11}-4$ & & Employed clinically for lesion treatment to promote enamel regeneration ${ }^{60}$ \\
\hline & RADA16 & YIGSR \& GRGDS & Provided immediate hemostasis and accelerated liver tissue regeneration in rats ${ }^{34}$ \\
\hline & RADA16 & IKVAV & Brain tissue regeneration in rats ${ }^{39}$ \\
\hline & RADA16 & Substance P & $\begin{array}{l}\text { Enhanced angiogenesis and promoted full recovery of } \\
\text { ischemic hind limb in rat model }\end{array}$ \\
\hline & RADA16 & P24 (BMP) & Along with PLGA promoted bone tissue regeneration in rats ${ }^{58}$ \\
\hline & PA & BMP-2 & Loaded in collagen sponge and promoted bone regeneration in rat femur ${ }^{61}$ \\
\hline & RADA16 & & Mucosal regeneration in rat-middle ear $^{63}$ \\
\hline \multirow[t]{2}{*}{2012} & RADA16 & & Peripheral nerve regeneration in rats ${ }^{36}$ \\
\hline & RADA16 & PRG \& KLT & Promoted angiogenesis in CAM model ${ }^{48}$ \\
\hline \multirow[t]{5}{*}{2011} & RADA16 & & Promoted nerve regeneration in hamster model ${ }^{38}$ \\
\hline & RADA16 & FGF-2 \& PDGF-BB & Promoted angiogenesis and prevented cardiac fibrosis in mice ${ }^{44}$ \\
\hline & RADA16-4G & BHMP1 & Neural regeneration in rat spinal cord ${ }^{39}$ \\
\hline & PA & VEGF \& FGF-2 & Promoted angiogenesis in CAM model ${ }^{51}$ \\
\hline & RADA16 & PRP & Complete enamel regeneration in dogs ${ }^{57}$ \\
\hline \multirow[t]{8}{*}{2010} & RADA16 & & Hemostasis in rat kidney ${ }^{33}$ \\
\hline & PA & IKVAV & Spinal cord regeneration in rats and mouse $\mathrm{e}^{41}$ \\
\hline & RADA16 & & Transplanted with cells in mice to reduce infarct size of myocardium ${ }^{46}$ \\
\hline & PA & TGF- $\beta 1$ & Promoted articular cartilage regeneration in rabbit ${ }^{54}$ \\
\hline & RADA16 & & Filled in PEEK cages to promote femur bone regeneration in rats ${ }^{56}$ \\
\hline & PA & RGDS, S(P) & Bone regeneration in rat femoral defect ${ }^{59}$ \\
\hline & PA & VEGF \& FGF-2 & Growth factor delivery to pancreatic islets to promote angiogenesis ${ }^{62}$ \\
\hline & KLD12 & $\begin{array}{l}\text { TGF- } \beta 1 \text {, } \\
\text { dexamethasone \& IGF-1 }\end{array}$ & Regenerated full thickness articular cartilage in rabbit ${ }^{53}$ \\
\hline \multirow[t]{2}{*}{2009} & RADA16 & & Reconstruction of acute traumatic brain injury in rats ${ }^{37}$ \\
\hline & PA & & Promoted vascularization of connective tissue in mice ${ }^{50}$ \\
\hline 2008 & PA & & Loaded in $\mathrm{Ti}-6 \mathrm{Al}-4 \mathrm{~V}$ porous foam to promote bone regeneration in rat femoral model ${ }^{60}$ \\
\hline \multirow[t]{2}{*}{2007} & RADA16 & & Promoted spinal cord regeneration in rats ${ }^{36}$ \\
\hline & RADA16 & SDF-1 & Growth factor delivery promoted cardiac function in rat myocardial infarcted model ${ }^{43}$ \\
\hline \multirow[t]{5}{*}{2006} & RADA16 & & Demonstration of multiple tissue hemostasis in hamster, rat and mice models ${ }^{35}$ \\
\hline & RADA16 & & Promoted regeneration of optic tract in hamster models ${ }^{38}$ \\
\hline & RADA16 & PDGF-BB & Growth factor delivery reduced infarct size in myocardial infarcted rats ${ }^{42}$ \\
\hline & RADA16 & IGF-1 & Growth factor delivery reduced infarct size in myocardial infarcted rats ${ }^{45}$ \\
\hline & PA & VEGF \& FGF-2 & Promoted angiogenesis in rat cornea ${ }^{49}$ \\
\hline
\end{tabular}


scaffolds that can mimic the structure and function of native ECM. In vivo, the 3D microenvironment comprises of fibrous ECM along with the significant proportion of hydrogels such as glycosaminoglycans, hyaluronic acid and proteoglycans. These hydrogels structures impart compressive resistance to the ECM and also facilitate easy migration of signaling molecules and soluble factors. ${ }^{21}$ SAP hydrogels has nanofibrous geometry that is dually advantageous to mimic the in vivo 3D environment for easy integration with the host tissue and to regenerate the damaged tissue. Examples of SAPs with functional motifs and growth factors that have been demonstrated to aid in tissue regeneration at in vivo in animal or clinical test are given in Table 1.

\section{Peptide amphiphiles}

Peptide amphiphiles (PAs) are another class of SAPs that can self-assemble into biomaterials. ${ }^{9,22,23}$ Essentially, simple chemistry is used to obtain a broad class of molecules by incorporation of a short hydrophobic domain onto one end of a hydrophilic oligopeptide sequence. The chemical structure comprising of four key structural domains in PAs is shown in Fig. 3A. The first hydrophobic domain (domain 1) typically consists of alkyl chains that can be tuned to different chain lengths or different hydrophobic components that in turn imparts the hydrophobicity for self-assembly. A short peptide sequence (domain 2), that is immediately adjacent to the domain 1 , induces the assembly of molecules into higher order structures by promoting $\beta$-sheet formation through intermolecular hydrogen bonds. The third domain (domain 3) comprises of charged amino acids that dictates the properties of the PA (such as solubility) and induces the self-assembly of

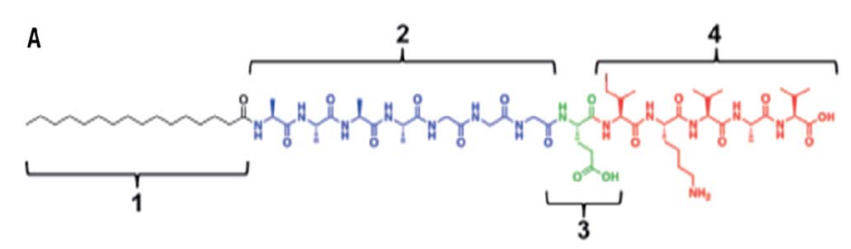

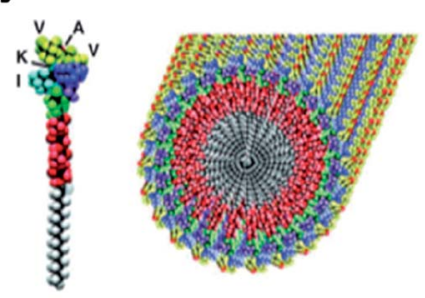

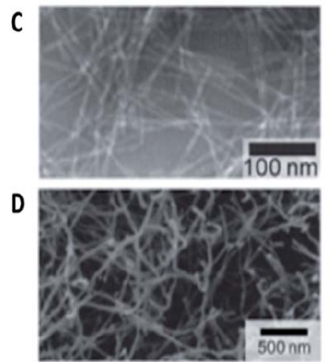

Fig. 3 (A) Molecular structure of a representative peptide amphiphile, showing the four key structural domains. (B) Molecular graphics illustration of an IKVAV-containing peptide amphiphile molecule and its self-assembly into nanofibers, (C) transmission electron microscopy (TEM) micrograph of IKVAV nanofibers; (D) SEM micrograph of an IKVAV nanofiber gel network. Figure and legend reproduced with permission from ref. 9. Figures reproduced from Fig. 1 of ref. 9. Copyright 2009, John Wiley and Sons. molecules by changing $\mathrm{pH}$ or concentration and type of added salt. The fourth domain (domain 4) consists of an oligopeptide sequence usually of bio-interactive motifs that can interact with cells or other biomolecules. If domain 4 has a sufficient number of charged amino acids to provide solubility and charge screening possibilities, then domain 3 is not necessary for the fabrication of the PA. These PA systems offer lots of flexibility and allow users to implement their own modifications and thus expand the versatility of the materials for use in diverse biomedical applications..$^{9,22}$ As with other SAPs, PA can be functionalized with specific cell adhesion peptides, e.g. IKVAV (Fig. 3B).

\subsection{Mechanism of assembly}

The tuning of self-assembled structures is very important to precisely control and improve their stability and viscoelastic properties. Although self-assembly involves a variety of physical forces, it is the hydrophobic forces that play an integral role in driving this process. ${ }^{15,24}$ Many workers have found that the degree of hydrophobicity affects the nucleation and elongation rates of self-assembly. The higher the number of hydrophobic groups, the faster the self-assembly process and improvement of the mechanical properties of the system. ${ }^{15}$ The driving force for this assembly is based on two factors. The first is the hydrophobic collapse of domain 1 away from the aqueous environment and propensity for intermolecular hydrogen bond formation. ${ }^{9,22}$ The charged amino acids are screened away by the electrolytes in the physiological media, thereby minimizing the electrostatic repulsion. Furthermore, the alkyl tails are driven away by a hydrophobic collapse in the aqueous media, and intermolecular hydrogen bonds are formed parallel to the fiber axis. ${ }^{25}$ Intermolecular cross-linking of PA has also been achieved by incorporating cysteine moieties that can lead to the formation of high molecular weight fibrous polymers. ${ }^{26}$ The conical shape of amphiphiles comprising a hydrophilic head with its hydrophobic tail, similar to lipid molecules, contributes to formation of many different structures depending upon the composition in the domains. For e.g. PAs synthesized with mono or di-alkyl tails associate to form triple helical structures in collagen. ${ }^{26}$ Modifications in the domain results, in the conical shape of PA to assemble into nanofibrous structures with the diameter of $10 \mathrm{~nm}$ to few micrometers. ${ }^{9,22,26}$ The selfassembled fibrillar structures form self-supporting three dimensional networks, mimicking the native ECM. These structures are also able to deliver GFs and other bioactive molecules at the required site. In second generation PA-based materials, bioactive moieties or signaling molecules were incorporated into the peptides to obtain the desired biological activity. In this strategy, the presence of appropriate $\mathrm{pH}$ or salt content, the unassembled PAs can couple with each other and the bioactive motifs such as GFs, cell specific moieties or cells. ${ }^{9,22}$ Understanding the effects of electrostatic interactions on the self-assembly of PAs will help us in particular to mimic the 3D ECM microenvironment for tissue function and regeneration. 
Apart from these two classes, researchers have developed different classes of self-assembling peptide nanofibrous scaffolds. Schneider investigated the gelation of $\beta$-hairpin peptides, while others have investigated a range of other supramolecular structures that use peptides for folding and gelation. ${ }^{17}$ To date, many researchers have constructed various supramolecular structures including self-assembled nanofibers for diverse applications.

\section{Self-assembling peptide nanofiber scaffolds in tissue regeneration in vivo}

Since each tissue differs morphologically and physiologically, their respective tissue ECM also varies significantly. The modular nature of SAPs allows design of the peptide scaffolds with bioactive motifs and growth factors to support the survival and growth of the different target cell types. The motifs and bioactive factors recapitulate the cell signaling mechanisms by ligand specific interactions in ECM that modulate regeneration of specific tissues. ${ }^{27}$ There are multiple reports of SAP enabled tissue regeneration in vitro, in tissue culture models. ${ }^{28-31}$ In the past 7-8 years (approximately), there has been rapid growth in employing SAPs to regenerate several tissues in vivo. The supramolecular nature of SAPs prevents rapid blood clearance of drugs and growth factors thereby allowing adequate exposure to the target tissue/organ to aid tissue regeneration.

\subsection{Immunological characteristics}

There is not much information available on SAP immunogenicity. It has been suggested that the immunogenicity or lack thereof many be due to the presence or absence of immune epitopes on the surface of SAP based structures. ${ }^{27}$ SAPs have been tested as adjuvants in vaccine development with mixed results. For example, complications involving SAP

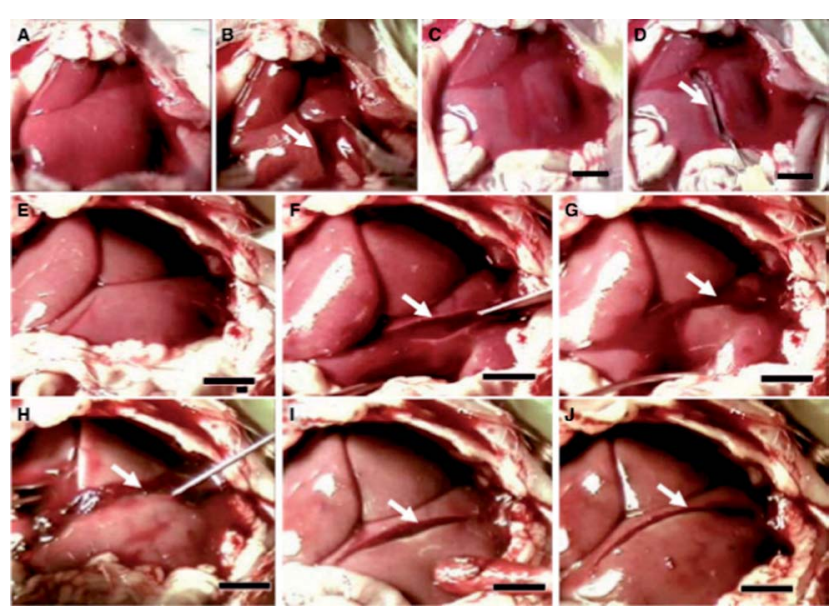

Fig. 4 Rat liver hemostasis, as illustrated by a series of pictures taken when the skin covering intraperitoneal cavity was excised to expose the liver. (A-D) Sagittal cut to the liver. Complete cessation of bleeding was found in D after SAP treatment; $(E-J)$ transverse cut, complete cessation of bleeding after treatment in $\mathrm{H}, \mathrm{I}$ and $\mathrm{J}$. Figure reproduced from Fig. 3 of ref. 35. Copyright 2006, Elsevier. immunogenicity have been documented. Peptide-based vaccines that were being developed against pneumococcal disease were reported cause a fast and fatal anaphylaxis in mice after administration of a booster injection of the peptide. ${ }^{27}$

On the other hand, SAPs that lack immune epitopes are not immunogenic on their own. ${ }^{27}$ Hence, they can potentially be used as tissue engineering scaffolds in regenerative medicine. In the following sections, we discuss examples of SAPs that have been evaluated for use in regenerative medicine applications.

\subsection{Hemostasis}

Homeostasis refers to the maintenance of a stable internal environment within the body. In the case of injuries with gaping wounds, hemostatic mechanisms act to minimize blood loss while regulating blood $\mathrm{pH}$. The ionic complementary SAPs, RADA and EAK have demonstrated their capability in minimizing blood loss at the wound site by providing immediate hemostasis in vivo in less than 20 seconds at multiple wound sites ranging from skin, liver, brain, kidney and lungs (Fig. 4). RADA 16 was decorated with YIGSR and GRGDS functional motifs by Cheng and co-workers who then studied their capacity for providing hemostasis in the rat liver. The author reported that the functionalized nanopeptides not only provided immediate hemostasis but also accelerated liver tissue regeneration in the rat liver model. ${ }^{34}$ The exact mechanism of action at injury site is still unclear, but it is been hypothesized that the injected SAP solution permeates into the wound region, making tight contact with the wound edges through electrostatic interactions. The SAPs are then thought to self-assemble into

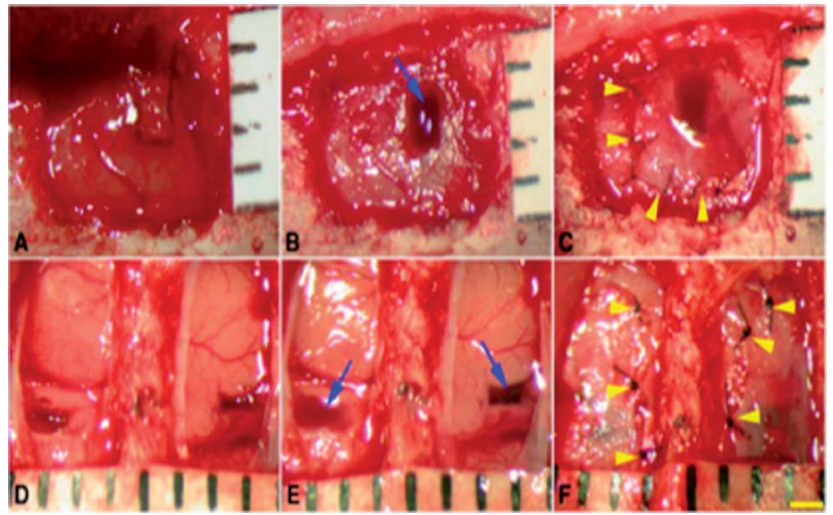

Fig. 5 Experimental brain lesions for testing efficacy of RADA SAPs. (A-C) Experimental procedures performed unilaterally on the brain's right hemisphere. (A) At a distance of $2 \mathrm{~mm}$ to the right of the bregma, a rectangle of $1 \times 2 \mathrm{~mm}$ was cut to a depth of $2 \mathrm{~mm}$. The excised tissue was removed with a vacuum pump-aided aspirator. (B) SAPs were administered to fill the cavity after the bleeding stopped (arrow). (C) The dura was sutured with 11-0 surgical sutures (arrowheads). (D-F) Bilateral lesions. Experimental and control lesions were performed on both sides of each brain (D). (E) SAPs were administered to fill the right cavity (arrow) and saline was administrated into the left cavity as control (arrow). (F) Both wounds were closed by suturing the dural opening (arrowheads). Figure reproduced from Fig. 1 of ref. 37. Copyright 2009, Elsevier. 
nanofibers that in turn fill the irregular voids at wound site and seal the wound, thereby minimizing the bleeding. ${ }^{32-35}$

\subsection{Neural regeneration}

In past five to six years, SAPs have proven to be effective in treatment of central nervous system (CNS) injuries by enabling the regeneration of brain and spinal cord tissues in vivo. Both ionic complementary SAPs and PAs have been tested in vivo in animal models for tissue regeneration. RADA peptide scaffolds have been demonstrated to bridge the traumatic injury gap between the nerve stumps in brain and spinal cord by integrating well with the host tissues and promoting two-way migration of cells. ${ }^{36,37}$ Fig. 5 shows an example of a model gap injury in rat models for testing the efficacy of RADA SAPs. EllisBehnke et al. injected a solution of RADA into the optic tract of midbrain wound in Syrian hamster pups. ${ }^{38}$ Subsequent histological examination showed that the injected SAP integrated well with wound and stimulated neurite extension and active synapse formation through axon regeneration that helped in the regeneration of the optic tract and restored of animal vision. In 2011, Liang and co-workers used MEMRI $\left(\mathrm{Mn}^{2+}\right.$-enhanced MRI) to measure and monitor the real time regeneration of CNS in a chronic injury model along with in vivo real-time feedback system to monitor every stage of the optical tract healing and regeneration process. ${ }^{38}$ Very recently in 2013, RADA peptides decorated with the neurite promoting laminin epitope IKVAV have been employed for neural stem cell encapsulation for treating traumatic brain injuries. ${ }^{39}$ The RADA16-IKVAV encapsulation of NSCs resulted in minimal astrocytic scar formation with improved neuronal differentiation in comparison to either RADA16-IKVAV only and or NSCs only in the regeneration of brain tissue. In 2011, Cigognini and co-workers showed that functionalization of RADA16 with bone marrow homing peptide (BHMP1) could be improved by the insertion of a long glycine spacer (4G) for promoting neural tissue regeneration. ${ }^{39}$ The authors injected RADA16-4G-BHMP1 into lesion sites of acutely injured spinal cords in rats and observed the enhancement of neuronal in-growth accompanied by axonal regeneration after 8 weeks. Another $\beta$-sheet forming peptide $\mathrm{K}_{2}(\mathrm{QL})_{6} \mathrm{~K}_{2}(\mathrm{QL})_{6}$ was also employed for spinal cord reconstruction in rat models by Fehlings and co-workers in $2013 .^{40}$ In the subsequent year, Fehlings further demonstrated a synergistic effect of neural stem/progenitor cells (NPCs) transplantation with $\mathrm{QL}_{6} \mathrm{SAP}$ in rat spinal cord injury models. Combined transplantation of NPCs with SAP in cervical spinal cord injury promoted the neuroprotection of spinal cord at twelve weeks after injury and played a significant role in the recovery of forelimb neural function in mice. ${ }^{40}$

PAs functionalized with IKVAV have also been reported to improve functional recovery after spinal cord injury in rats and mice, in two different injury models of contusion and compression..$^{41}$ The injected PA-IKVAV increased the number of oligodendroglial cells that are responsible for the formation of myelin sheaths in CNS. The regeneration of functional axons resulted in the behavioral improvement of hind limb functions. The influence of aligned nanofibrous peptide amphiphile
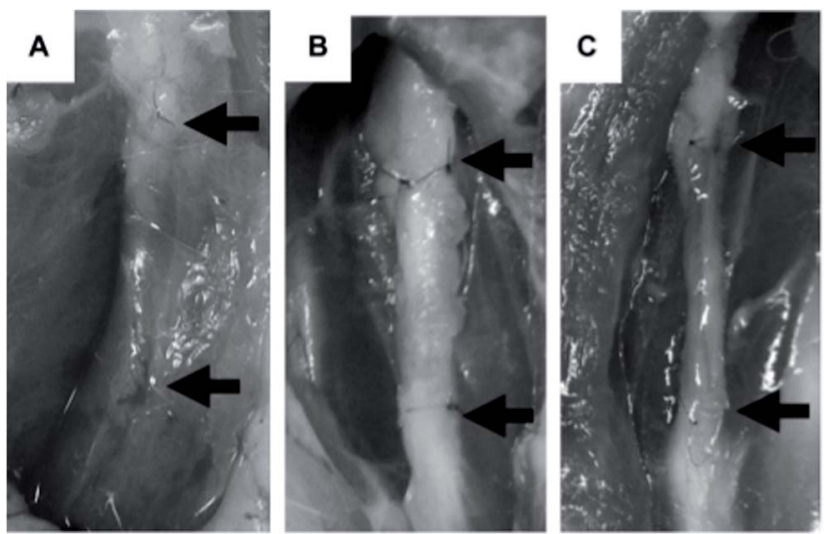

Fig. 6 Rat sciatic nerves at 12 weeks bridging surgery to heal defects caused by excision of a segment located between the two arrows. (A) No nerve regeneration was observed in the negative, unbridged control; scar tissue filled the original defect site. (B) Nerve bridging was observed in the autograft group. (C) Nerve regeneration was observed in the PLGA/RGDS-PA group. PLGA conduit had degraded completely, leaving behind regenerated nerve structure. Figure reproduced from Fig. 6 of ref. 41. Copyright 2014, Elsevier.

hydrogels on peripheral nerve regeneration was studied by Li and co-workers recently. PAs functionalized with RGD motifs were encapsulated with Schwann cells and subsequently aligned using PLGA tubes to form aligned PAs. ${ }^{41} \mathrm{~A}$ sciatic nerve injury of $12 \mathrm{~mm}$ was created in mice and was bridged with aligned peptide amphiphile conduits between the nerve stumps (Fig. 6). After a 12 week study, the authors showed that PLGA/ RGDS-PA and PLGA/backbone-PA was able to promote sciatic nerve regeneration. A thermal sensitivity study performed showed that implantation of PA conduits enhanced the recovery of sensory function of their hind limbs.

\subsection{Angiogenesis and cardiac tissue regeneration}

RADA SAP systems have also been tested as injectable scaffolds for cell delivery in cardiac tissue regeneration. These SAPs contained growth factors and bioactive motifs to promote angiogenesis and tissue regeneration by the sustained release of GFs from the SAP matrix. Non-specific binding of SAPs with platelet-derived growth factor (PDGF-BB) through weak molecular interactions provided sustained delivery of PDGF-BB growth factor compared to the control (PDGF-BB without SAP). The mixture was injected into 3 locations within infarcted rat myocardium, where it reduced the infarct size in the myocardial infarction-induced rats, as demonstrated by Hsieh and coworkers. ${ }^{42}$ Segers and co-workers also induced myocardial infarction in Sprague-Dawley rats and demonstrated that tethering of metalloproteinase matrix-2 (MMP-2) protease resistant stromal cell-derived factor-1 (SDF-1) into a RADA16 scaffold induced migration of cardiac endothelial progenitor cells into the infarcted regions. ${ }^{43}$ They have also showed that tethering of SDF-1 to RADA 16 restored cardiac function in rats due to the sustained delivery of the growth factor in vivo, which facilitated the chemotaxis of stem cells and progenitor cells, accompanied by improvement of capillary densities and recruitment of 
$\mathrm{CXCR} 4^{+} / \mathrm{c}-\mathrm{Kit}^{+} / \mathrm{Flk}-1^{+}$cells. Sometimes the delivery of a single growth factor is not sufficient in inducing specific desired behavior. Hence, Kim and co-workers have injected dual growth factors PDGF-BB and FGF-2 with RADA 16 matrix for sustained delivery of growth factors within the infarcted myocardium in rat models. Each growth factor has its own cellular specific functions. ${ }^{44}$ The adsorption of both FGF-2 and PDGF-BB onto RADA 16 induced angiogenesis and arteriogenesis by recruitment of endothelial and vascular smooth muscle cells respectively, which in turn enhanced vascular network formation and improved cardiac functions. The combination of two synergistic growth factors improved all hemodynamic parameters and activated signaling processes for repairing and regeneration of cardiac tissues in rat models. In another similar study, insulinlike growth factor 1 (IGF-1) was delivered using biotinylated RADA-II. ${ }^{45}$ The sustained release of IGF-1 in conjunction with cell therapy significantly improved the systolic function of myocardial infarcted rat hearts. RADA-16 SAPs have also been transplanted with Sca-1 cells into myocardial infarcted mouse rats, suggesting the efficacy of SAPs as a vehicle for therapeutic cell delivery. ${ }^{46}$ The transplanted cells were sustainably delivered over 2 weeks to mouse myocardium. PDGF-BB and vascular endothelial growth factor (VEGF) were up-regulated, and the angiogenesis that was induced was able to restore function to the affected cardiac tissues. Apart from cardiac tissue, RADA and PAs also promoted angiogenesis in a number of other organs in vivo. In 2013, Kim et al. demonstrated the regeneration of functional blood vessels in the hind limbs of ischemic rats using RADA 16-II peptide scaffolds. ${ }^{47}$ The workers delivered neuropeptide Substance $P$ for 28 days by immobilizing it with RADA scaffolds (Fig. 7). The RADA scaffolds provided a 3D microenvironment that promote angiogenesis by recruiting mesenchymal stem cells (MSCs) to the injury site and improved the vascular density to $95 \%$. However, the mechanism for MSC recruitment by Substance $P$ delivered within the RADA scaffolds has still not been elucidated. Zhang and co-workers evaluated the in vivo angiogenic activities of two functionalized peptide scaffold hydrogels RADA 16-PRG (2-unit RGD binding peptide) and RADA16-KLT (VEGF mimicking peptide) using the chick embryo chorioallantoic membrane (CAM) assay. ${ }^{48}$ Very recently there were some advancements in loading the SAP in elastomeric or demineralized matrix to promote the cell adhesion on the modified surfaces to improve the regenerative properties of the scaffold. RADA16 undergoes spontaneous assembly when loaded into partially biodegradable elastomeric membranes comprising poly (caprolactone 2-(methacryloyloxy) ethyl ester) (PCLMA). The composite has been evaluated as a scaffold into mouse MI models. Subcutaneous adipose tissue-derived progenitor cells (subATDPCs) were loaded into the PCLMA-SAP matrix and injection of the composite mixture facilitated the cell delivery to the infarcted myocardium, resulting in regeneration after 3 weeks. ${ }^{48}$

In vivo studies of these functionalized peptide scaffold hydrogels showed induced sprouting of endothelial cells along with abundant capillary vessel invasion when tested in CAM tissue. Other PAs that were modified with heparin binding groups (HBPA) to influence the capture of functional proteins like FGF-2, VEGF and bone morphogenic protein (BMP), were also evaluated for their ability to promote angiogenesis in vivo. ${ }^{\mathbf{4 9}}$ HBPAs loaded with VEGF and FGF-2 and implanted into rat corneas, were demonstrated to promote angiogenesis. It was observed that the bioactive factors were released slowly in HBPA hydrogels, resulting in a significant amount of vascularization that was observed after the assessment of animals on 10th day of the rat corneal assay. In another study, Stupp and co-workers evaluated the tissue reaction of HBPA-Heparan Sulfate (HS) hydrogels in skin in vivo by implanting the materials subcutaneously in mouse models to study their microvascular effects within a dynamic skinfold chamber. ${ }^{50}$ Their study showed that these materials were biocompatible and were remodeled into vascularized connective tissue after 60 days without any adverse effects. In 2011, Stupp developed a bioactive assembled membrane using hyaluronic acid (HA)-HBPA to promote angiogenesis. ${ }^{51}$ The presence of heparin $(0.5 \mathrm{wt} \%)$ resulted in sustained release of growth factors (FGF-2 and VEGF) and induced angiogenesis as determined by a CAM assay. The

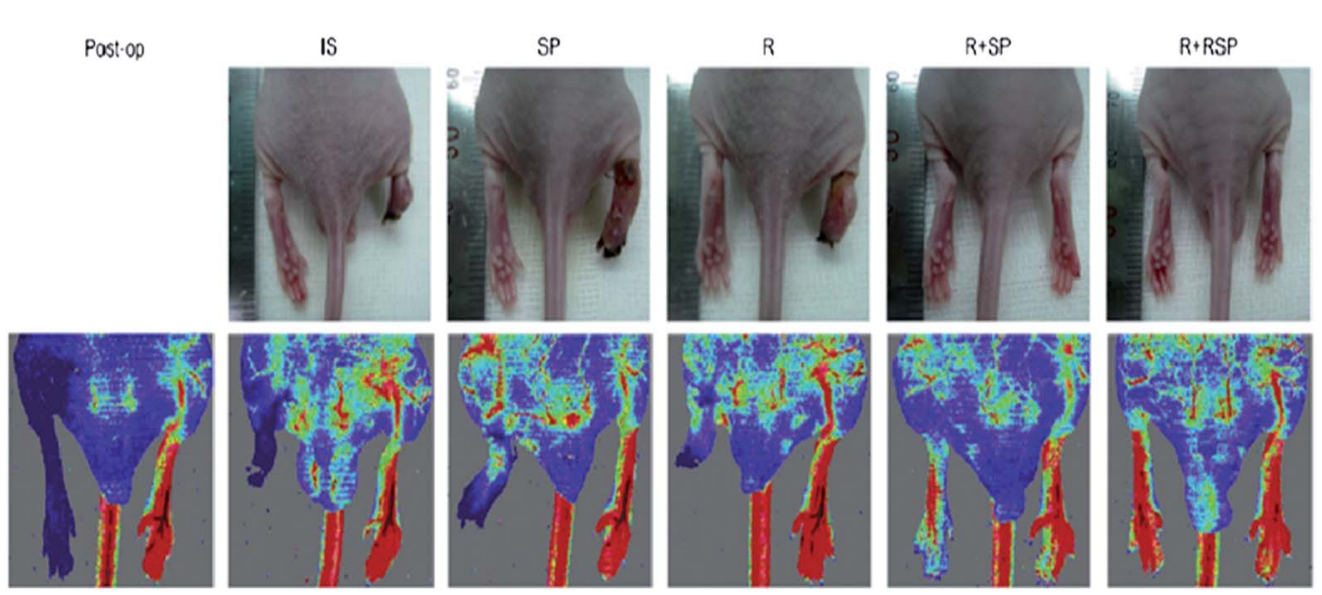

Fig. 7 Laser Doppler Perfusion images (LDPI) after the injection of bioactive peptides to represent the full recovery of ischemic hind limb after 28 days. Figures reproduced from Fig. 7 of ref. 47. Copyright 2013, Elsevier. 
results and findings of these studies show that this peptide amphiphile structures promotes significant amount of tissue vascularization that can be employed as wound dressings for chronic skin wounds and in several tissue regenerative strategies.

\subsection{Cartilage regeneration}

Despite the many in vitro studies showing potential for SAP enhancement of cartilage regeneration, ${ }^{52}$ there are only a few reports on in vivo chondrogenesis using SAPs. To regenerate cartilage tissue, primary chondrocytes or MSCs were encapsulated within SAPs to promote synthesis of proteoglycans and collagen for cartilage ECM reconstruction. Chondrogenic factors (CF) such as Transforming Growth Factor- $\beta 1$ (TGF- $\beta 1$ ) and IGF-1 were absorbed or tethered onto SAPs to respectively promote proteoglycan synthesis in bone marrow stromal cells (BMSCs) and chondrocytes in vitro. ${ }^{52} \mathrm{KLDL}$ is another ionic selfcomplementary peptide which has been employed in in vivo cartilage regeneration due to its relatively high mechanical strength of $120 \mathrm{~Pa}$ (for 1\% conc.) compared to those of other RADA scaffolds (that average about $46 \mathrm{~Pa}$ ). ${ }^{53}$ In 2010, Miller et al. encapsulated BMSCs in KLDL peptide along with CFs (TGF- $\beta 1$, dexamethasone and IGF-1) to regenerate full thickness articular cartilage defects in rabbit models. ${ }^{53}$ Peptide amphiphiles with TGF-binding domain were synthesized by Stupp and co-workers was employed in rabbit models for articular cartilage defects. ${ }^{54}$ The presence of TGF- $\beta 1$ binding epitopes in the PAs promoted chondrogenesis with significant production of glycosaminoglycans and collagen for articular cartilage reconstruction in rabbit models.

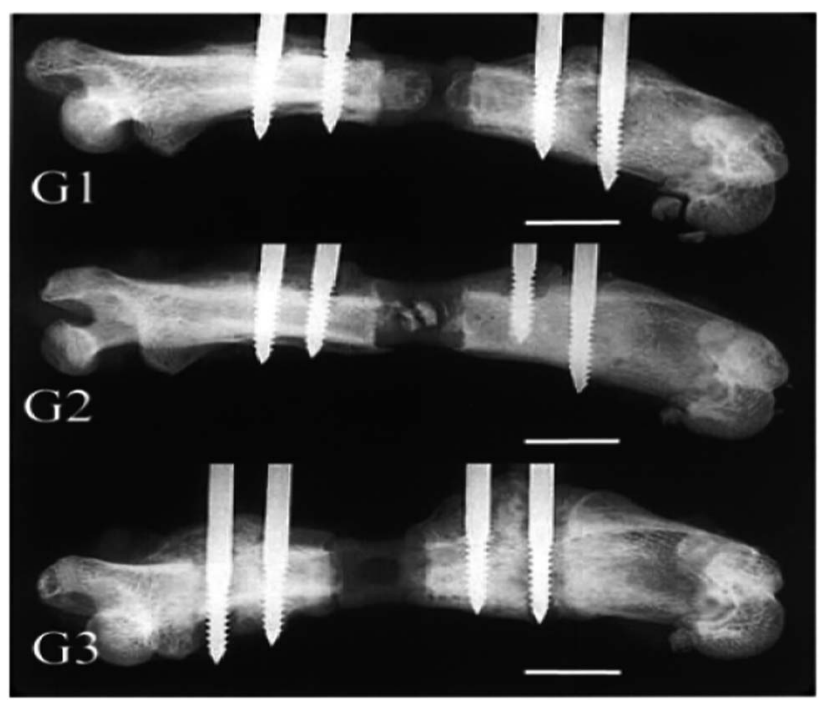

Fig. 8 Representative soft X-ray radiographs of specimens after 28 days of implantation. G1, PEEK cage with SAPS. New bone formation is seen inside the PEEK cage. G2, PEEK cage with autologous bone. The transplanted bone was left behind and some degree of contact was obtained between the transplanted bone and the new bone. G3, PEEK cage only. Little to no bone formation is noted. The average bridging ratios of femoral bone defects was $78.9 \%$ for G1, $96.5 \%$ for G2, and $29.5 \%$ for G3. Figure and legend reproduced from Fig. 3 of ref. 56. Copyright 2010, Cognizant Communication Corporation.

\subsection{Bone repair and regeneration}

RADA SAPs and PAs have also been tested in vivo as scaffolds for promoting regeneration of bone and enamel. In 2006, RADA scaffolds were employed to repair and regenerate bone defects in calvaria of mice. ${ }^{55}$ Later, RADA was combined with other synthetic polymers to improve their mechanical strength and used to regenerate the load-bearing bones. ${ }^{56}$ PEEK (Polyetheretherketone), a material used in spinal fusion procedures in clinical applications was combined with RADA SAP to form a hybrid scaffold. The RADA were used to internally fill in Polyetheretherketone (PEEK) cages and were employed in the repair of $5 \mathrm{~mm}$ bone defects in rat femurs (Fig. 8). The RADA/PEEK composites facilitated the osteogenesis inside the cages, but complete regeneration of the femur bone was not achieved. The authors reported that using BMSCs that produce paracrine signaling molecules in SAPs could be a possible solution for complete regeneration of bone. RADA16 along with MSCs and Platelet-Rich Plasma (PRP) as signaling the molecule, promoted a complete enamel regeneration in dogs, while RADA alone and RADA/MSCs induced partial bone formation. ${ }^{57}$ Recently in 2013, a hybrid scaffold composed of RADA-P24-PLGA promoted in vivo ectopic bone mineralization and regeneration in Wister rats. ${ }^{58}$ P24 is a bone morphogenic protein (BMP) which has been reported to induce ectopic bone formation in vivo. This composite scaffold has higher mechanical strength and

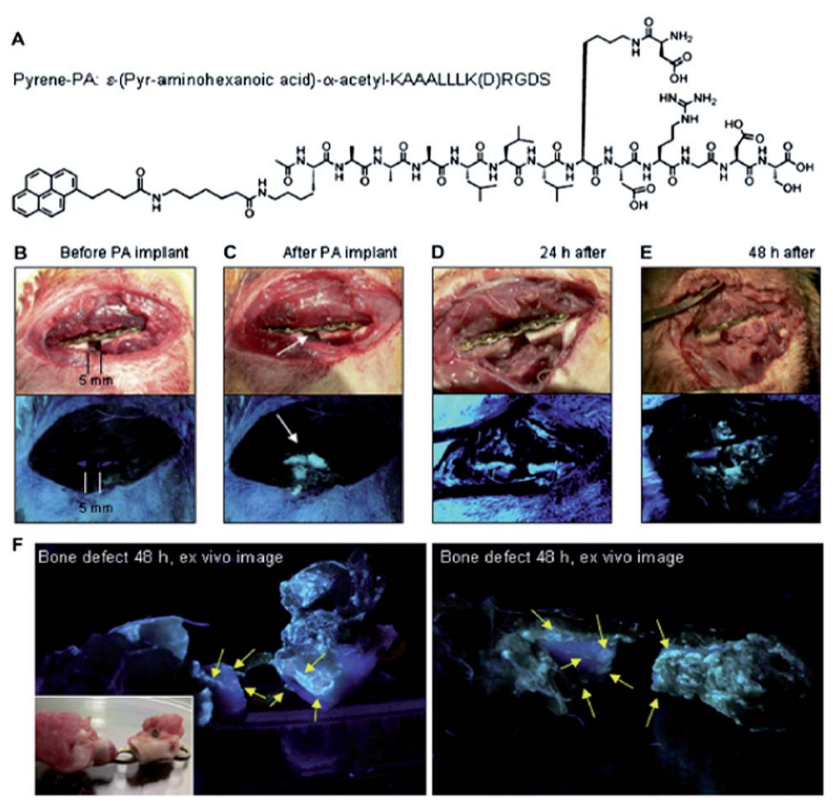

Fig. 9 Presence of PA gel within the defect, before, during and after surgery. (A) Chemical structure of the fluorescent pyrene-containing molecule used to determine PA gel positioning within the defect. Photographs depict (B) a $5 \mathrm{~mm}$ wide critical size defect prior to and (C) immediately after fluorescent PA gel implantation (white arrow pointing at the location of fluorescent PA). At both $24 \mathrm{~h}$ (D) and $48 \mathrm{~h}$ (E) after implantation, fluorescent PA gel material was observed to be dispersed but still within and around the fracture site while coating local muscle tissue and (F) the outer and inner surface of the bone. Figure and legend reproduced from Fig. 2 of ref. 62. Copyright 2010, Elsevier. 
promotes ossification in 4 weeks and regenerated the ectopic bone in 8 weeks (Fig. 9). Demineralized bone matrix (DBM) was modified with RADA16-I SAP to improve the cell adhesive properties. In the modified DBM, RADA was self-assembled into nanofibers on the surface and along the pore walls of DBM, When the composite was transplanted into latero-illium of mice, RADA16-I enriched DBM was found to have attracted more osteogenic stem cells from bone marrow and showed enhanced osteogenesis compared to DBM alone. ${ }^{59}$ The authors also demonstrated marrow-enriched the DBM/SAP repaired a 20 $\mathrm{mm}$ femur bone defect in goat. ${ }^{59}$ Very recently in 2014 , Kim and co-workers reported the use of another $\beta$-sheet forming SAP, KLD12 to treat osteoarthritis (OA) in a rat knee model. Rats with induced OA in their knees were injected with bone marrow stem cells encapsulated with SAPs. The result decreased cartilage destruction or chondrocyte apoptosis, suggesting that the SAPS inhibited the OA. ${ }^{60}$

Another class of complementary peptide $\mathrm{P}_{11^{-4}}$ was used to treat class V enamel lesions in a clinical safety study (Fig. 10). The group comprised of seven females and eight males with a mean average age of $34.4 \pm 12.7$ years. $\mathrm{P}_{11}-4$ solution was directly applied to lesion surface and the subjects were reviewed at 4, 8, 30 and 180 days. Aggeli and co-workers had previously shown the ability of $\mathrm{P}_{11}$-4 to nucleate the hydroxyapatite crystals de novo. $\mathrm{P}_{11}-4$ was able to assemble into 3D fibrillar scaffolds at the site of lesion, directed by environmental conditions $(\mathrm{pH} \&$ salt concentration) and promoted peptide induced enamel remineralization of hydroxyapatite crystals. A clinical safety study of $\mathrm{P}_{11}-4$ concluded that treatment with the peptide repaired the dental lesions and regenerated the enamel 30 days after treatment and remained stable at 180 days (Fig. 10). ${ }^{61}$ This treatment offers unique advantages than other "filling without drilling" procedures and has been commercialized as Curodont $^{\mathrm{TM}}$ in 2012 for clinical use in Europe.

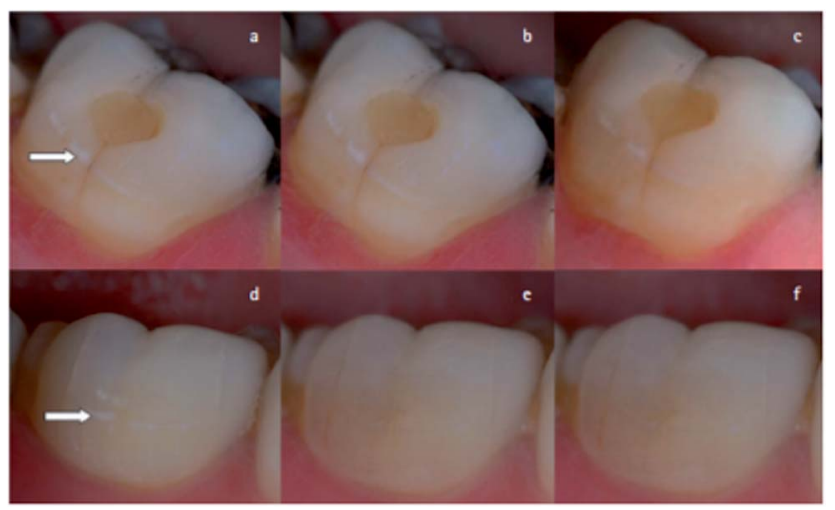

Fig. 10 Examples of clinical appearance of two class $V$ caries lesions (arrow) in different subjects included in the study. Images selected to show the range of response to a single application of $\mathrm{P}_{11}-4$ with time. ( $a$ and d) Lesion appearance at baseline (D0); ( $b$ and e) and ( $c$ and f) appearance of same lesion at D30 and D180 respectively. Figure and legends reproduced from Fig. 3 of ref. 61. Copyright 2013, Nature Publishing Group.
In the Stupp laboratory, PAs were modified with bioactive epitopes, e.g. phosphorylated serine $\mathrm{P}(\mathrm{S})$ residues were incorporated in to the $\mathrm{PA}$ structures $[\mathrm{S}(\mathrm{P})-\mathrm{PA}]$ to generate a completely artificial bone-bioactive matrix that mimics Bone Sialo Protein (BSP), an element of bone bio-mineralization that favors hydroxyapatite nucleation along the crystallographic axis in physiological conditions in vivo. ${ }^{62}$ To enhance the bioactivity of the artificial matrix, RGDS-PA (PA molecules with the RGDS fibronectin epitope) was co-assembled with S(P)-PA molecules to induce osteogenesis in rat femoral defect model. The level of osteogenesis induced in animal models was statistically equivalent to that of clinically used allogeneic demineralized bone matrix (DBM). RGDS-S(P)-PA also favored the hydroxyapatite nucleation, which subsequently stimulated the osteoblasts to form new bone. Hybrid PA implants have also been made with collagen sponges and porous titanium to regenerate bone tissue in vivo. ${ }^{63}$ In 2013, Stupp and co-workers developed a HBPA-HS/ porous collagen hybrid scaffold to deliver BMP-2 and to regenerate $5 \mathrm{~mm}$ femur bone defects in vivo. The workers reported that, these hybrid scaffolds innervates the signaling mechanism with very small amount of BMP-2 to undergo ligand-receptor mediated signaling mechanism with heparan sulfate chains found within the ECM. These sulfated oligosaccharide chains bind non-covalently with BMP-2 and also with the fibronectin PAs via heparin-binding domains. The synergistic effect of these two signaling mechanisms facilitated the regeneration of femur bones in 6 weeks, in vivo. Similarly PAs were also loaded into Ti-6Al-4V porous foam promoted osteoconduction in rat femoral defect. ${ }^{64}$

\subsection{Regeneration in other organs}

Soft tissues like skin, mucosa, and islets were also regenerated in vivo using SAPs. Peptide amphiphiles (HBPA) were employed to deliver angiogenic growth factors for islet transplantation in diabetic mice. ${ }^{65}$ Implanted HBPA-GF induced significant neovascularization in the surrounding mice omental tissue resulting in the increased islet survival and function. Mucosal regeneration in the middle ear was achieved using RADA 16 scaffolds. Here, mucosal epithelial cells encapsulated in peptide matrix regenerated the damaged mucosa in the middle ear of Sprague Dawley rats. ${ }^{6}$ Very recently Uzunalli and coworkers demonstrated that PAs functionalized with YIGSR and RGD induced corneal stroma regeneration in rabbit models. ${ }^{67}$

\section{Summary and outlook}

The emerging capabilities of SAPs in bio-medical applications are leading up to the development of a new technological platform, peptide nanomedicine. It is envisioned that peptide nanomedicine will have important therapeutic applications in the near future. During the past 20 years, there has been rapid growth in exploiting the potential of these materials in regenerative medicine.

While there is more and more evidence supporting the safety and efficacy of SAPs, there is a paucity of information about their biodegradation in vivo. SAPs and in particular the peptide 
nanofibers (PNF) are considered biodegradable. They comprise amphiphilic peptides and peptides that are susceptible to enzymatic degradation in vitro by endopeptidases via hydrolysis. ${ }^{68}$ The degradation of PNF has been hypothesized by Mazza et $a l .{ }^{68}$ to proceed in one of two possible ways: (1) enzymatic degradation of PNFs into smaller fragments; or (2) disassembly from the two ends towards the middle. The end result in either case is the breakdown of PNFs into their amino acid components. Mazza et al. further demonstrated using dye labeledPNFs that these could be internalized by neural cells in vivo, in rat brains, and are then most likely degraded by also endopeptidases. Confirmation, however is still needed.

We have therefore highlighted some of the recent progress and potential of ionic complementary SAP and PA systems in tissue regeneration in vivo. Tailoring of scaffolds for specific target cells and tissues has been achieved by functionalization of the material with cell specific biomolecules that modulate signaling pathways that in turn control cell proliferation, differentiation and survival. The modular nature of SAPs combined with the functional moieties or growth factors result in the complex structures needed to regenerate specific target tissue(s). Functionalization of peptide scaffolds offers a unique advantage, which until now has not been utilized fully in tissue regeneration. The self-assembly is driven by interaction of several functional moieties, so countless numbers of structures can be obtained depending upon the interactions. Hence, we need a firm understanding about the available amino acids, their peptide and protein secondary structures to utilize this advantage.

3D Matrix Technology, a company commercializing PuraMatrix ${ }^{\mathrm{TM}}$ is currently conducting clinical studies on SAP systems as potential dental bone void filler and hemostats in the USA and in Europe. In 2014, PuraMatrix ${ }^{\mathrm{TM}}$ was also used clinically as a sealing material to reduce the post-operative peritoneal effusion after pelvic surgery. ${ }^{69}$

Finally, costs for the scaling-up production of peptides are a consideration. With solid state synthesis, small scale production is achievable but new innovative technologies for large scale production of peptides will become important not only for cost effectiveness but also to realize the various potential therapeutic applications.

In conclusion, recent advances in functionalization have paved the way for designing novel biological materials using self-assembled peptides to promote regeneration of human tissues. More and more studies of their utility in tissue regeneration are being reported and more clinical trials are underway. In the near future, these self-assembling peptide nanofibrous scaffolds will likely become available as a realistic therapeutic option for humans.

\section{Acknowledgements}

JP gratefully acknowledges financial support from the Swedish Research Council, Sweden (grant no. 2012-42315-94008-81).

\section{References}

1 B. P. Chan and K. W. Leong, Eur. Spine J., 2008, 17, 467-479; A. R. Boccaccini and J. J. Blaker, Expert Rev. Med. Devices, 2005, 2, 303-317.

2 S. Badra and J. K. Williams, J. Bioeng. Biomed. Sci., 2012, 2, 110.

3 Z. Ma, Z. Mao and C. Gao, Colloids Surf., B, 2007, 60, 137-157.

4 E. Schönherr and H. J. Hausser, Dev. Immunol., 2000, 7, 89101.

5 K. A. Piez, Matrix Biol., 1997, 16, 85-92.

6 E. C. Wu, S. Zhang and C. A. E. Hauser, Adv. Funct. Mater., 2012, 22, 456-468; S. Cavalli, F. Albericio and A. Kros, Chem. Soc. Rev., 2010, 39, 241-263.

7 Z. Luo and S. Zhang, Chem. Soc. Rev., 2012, 41, 4736-4754; S. Koutsopoulosa, L. D. Unsworth, Y. Nagaia and S. Zhang, Proc. Natl. Acad. Sci. U. S. A., 2009, 106, 4623-4628.

8 S. Zhang, Nat. Biotechnol., 2003, 21, 1171-1178.

9 J. B. Matson and S. I. Stupp, Chem. Commun., 2012, 48, 26-33; M. J. Webber, J. A. Kessler and S. I. Stupp, J. Intern. Med., 2009, 267, 71-88.

10 S. Zhang, Biotechnol. Adv., 2002, 20, 321-339.

11 J. Schnur, Science, 1993, 262, 1669-1676; Y. M. Lvov, R. R. Price, J. V. Seligner, A. Singh, M. S. Spector and J. M. Schnur, Langmuir, 2000, 16, 5932-5935.

12 C. A. Mirkin, R. L. Letsinger, R. C. Mucic and J. J. Storhoff, Nature, 1996, 382, 607-609.

13 X. Zhao and S. Zhang, Chem. Soc. Rev., 2006, 35, 1105-1110; G. M. Whitesides and B. Grzybowski, Science., 2002, 295, 2418-2421.

14 Y. Loo, S. Zhang and C. A. E. Hauser, Biotechnol. Adv., 2012, 30, 593-603; E. Kokkoli, A. Mardilovich, A. Wedekind, E. L. Rexeisen, A. Garg and J. A. Craig, Soft Matter, 2006, 2, 1015-1024; P. Kumaraswamy, R. Lakshmanan, S. Sethuraman and U. M. Krishnan, Soft Matter, 2011, 7, 2744-2754.

15 A. L. Boyle and D. N. Woolfson, Rational Design of PeptideBased Biosupramolecular Systems, John Wiley and Sons, Ltd., 2012, pp. 1639-1662.

16 S. Maude, L. R. Tai, R. P. W. Davies, B. Liu, S. A. Harris, P. J. Kocienski and A. Aggeli, Top. Curr. Chem., 2012, 310, 27-69.

17 R. P. Nagarkar and J. P. Schneider, Methods Mol. Biol., 2008, 474, 61-77; A. E. Hauser and S. Zhang, Chem. Soc. Rev., 2010, 39, 2780-2790; L. Sun and X. Zhao, Int. J. Nanomed., 2012, 7, 571-580.

18 S. Maude, E. Ingham and A. Aggeli, Nanomedicine, 2013, 8, 823-847.

19 X. Wang, A. Horii and S. Zhang, Soft Matter, 2008, 4, 23882395.

20 M. Reches and E. Gazit, Curr. Nanosci., 2006, 2, 105-111; G. A. Saracino, D. Cigognini, D. Silva, A. Caprini and F. Gelain, Chem. Soc. Rev., 2013, 42, 225.

21 J. K. Francis Suh and W. T. H. Matthew, Biomaterials, 2000, 21, 2589-2598. 
22 H. Cui, M. J. Webber and S. I. Stupp, Biopolymers, 2010, 94, 1-18.

23 J. C. Stendahl, M. S. Rao, M. O. Guler and S. I. Stupp, Adv. Funct. Mater., 2006, 16, 499-508.

24 H. Tsutsumi and H. Mihara, Mol. BioSyst., 2013, 9, 609-617. 25 Y. S. Velichko, S. I. Stupp and M. O. de la Cruz, J. Phys. Chem. $B, 2008,2326-2334$.

26 J. D. Hartgerink, E. Beniash and S. I. Stupp, Proc. Natl. Acad. Sci. U. S. A., 2002, 99, 5133-5138.

27 J. H. Collier, J. S. Rudra, J. Z. Gasiorowski and J. P. Jung, Chem. Soc. Rev., 2010, 39, 3413-3424; C. M. Smith, P. Bradding, D. R. Neill, H. Baxendale, F. Felici and P. W. Andrew, J. Immunol., 2011, 187, 1201-1206.

28 T. D. Sargeant, C. Aparicio, J. E. Goldberger, H. Cui and S. I. Stupp, Acta Biomater., 2012, 8, 2456-2465.

29 N. M. Buyé, T. Luque, D. Navajas and C. E. Semino, Tissue Eng., Part A, 2013, 19, 870-881.

30 T. Lu, T. Chen, Y. Zhai, Y. Ma and Y. Xiao, Soft Matter, 2013, 12, 79-87.

31 X. Wang, A. Horii and S. Zhang, Soft Matter, 2008, 4, 23882395.

32 T. Wang, X. Zhong, S. Wang, F. Lv and X. Zhao, Int. J. Mol. Sci., 2012, 13, 15279-15290.

33 H. Song, L. Zhang and X. Zhao, Macromol. Biosci., 2010, 10, 33-39.

34 T. Y. Cheng, H. C. Wu, M. Y. Huang, W. H. Chang, C. H. Lee and T. W. Wang, Nanoscale, 2013, 5, 2734-2744.

35 R. G. Ellis Behnke, Y. X. Liang, D. K. C. Tay, P. W. F. Kau, G. E. Schneider, S. Zhang, W. Wu and K. So, Nanomed. Nanotech. Biol. Med., 2006, 2, 207-215.

36 J. Guo, H. Su, Y. Zeng, Y. Liang, W. M. Wong, R. G. EllisBehnke, K. Fai and W. Wu, Nanomed. Nanotech. Biol. Med., 2007, 3, 311-321; H. Meng, R. Chen, L. Xu, W. Li, L. Chen and X. Zhao, Life Sci. J., 2012, 9, 42-46.

37 J. Guo, K. K. Gilberto Leung, H. Su, Q. Yuan, L. Wag, T. H. Chu, W. Zhang, J. K. Suen, G. K. P. Ng, W. M. Wong, X. Dai and W. Wu, Nanomed. Nanotech. Biol. Med., 2009, 5, 345-351.

38 R. G. Ellis Behnke, Y. Liang, S. You, D. K. C. Tay, S. Zhang and K. So, Proc. Natl. Acad. Sci. U. S. A., 2006, 103, 50545059; Y. Liang, S. W. H. Cheung, K. C. W. Chan, E. X. Wu, D. K. C. Tay and R. G. Ellis-Behnke, Nanomed. Nanotech. Biol. Med., 2011, 7, 351-359.

39 T. Y. Cheng, M. H. Chen, W. H. Chang, M. Y. Huang and T. W. Wang, Biomaterials, 2013, 34, 2005-2016; D. Cigognini, A. Satta, B. Colleoni, D. Silva, M. Donega, S. Antonini and F. Gelain, PLoS One, 2011, 6, 1-15.

40 Y. Liu, H. Ye, K. Satkunendrarajah, G. S. Yao, Y. Bayon and M. G. Fehlings, Acta Biomater., 2013, 9, 8075-8088; M. Iwasaki, J. T. Wilcox, Y. Nishimura, K. Zweckberger, H. Suzuki, J. Wang, Y. Liu, S. P. Karadimas and M. G. Fehlings, Biomaterials, 2014, 35, 2617-2629.

41 V. M. Tysseling, V. Sahni, E. T. Pashuck, D. Birch, A. Hebert, C. Czeisler, S. I. Stupp and J. A. Kessler, J. Neurosci. Res., 2010, 88, 3161-3170; A. Li, A. Hokugo, A. Yalom, E. J. Berns, N. Stepanopoulos, M. T. McClendon,
L. A. Segavia, I. Spigelman, S. I. Stupp and R. Jarrahy, Biomateials, 2014, 35, 8780-8790.

42 C. H. Hsieh, E. Davis, J. Gannon, C. MacGillivray and T. Lee, J. Clin. Invest., 2006, 116, 237-248.

43 F. V. Segers, T. Tokunou, J. Higgins, C. MacGillivray, J. Gannon and T. Lee, Circulation, 2007, 116, 1683-1692.

44 J. H. Kim, Y. Jung, S. H. Kim, K. Sun, J. Choi, H. C. Kim, Y. Park and S. H. Kim, Biomaterials, 2011, 32, 6080-6088.

45 M. E. Davis, P. C. H. Hsieh, T. Takahashi, Q. Song, S. Zhang, R. D. Kamm, A. J. Grodzinsky, P. Anversa and R. T. Lee, Proc. Natl. Acad. Sci. U. S. A., 2006, 103(21), 8155-8160.

46 M. Tokunaga, M. L. Liu, T. Nagai, K. Iwanaga, K. Matsuura, T. Takahashi, M. Kanda, N. Kondo, P. Wang, A. T. Naito and I. Komuro, J. Mol. Cell. Cardiol., 2010, 49, 972-983.

47 J. H. Kim, Y. Jung, B. S. Kim and S. H. Kim, Biomaterials, 2013, 34, 1657-1668.

48 X. Liu, X. Wang, A. Horii, X. Wang, X. Wang, L. Qiao, S. Zhang and F. Cuia, Nanoscale., 2012, 4, 2720-2727; C. S. Botija, et al., Am. J. Transl. Res., 2014, 6, 291-301.

49 K. Rajangam, H. A. Behanna, M. J. Hui, X. Han, J. F. Hulvat, J. W. Lomasney and S. I. Stupp, Nano Lett., 2006, 6, 20862090.

50 S. Ghanaati, M. J. Webber, R. E. Unger, C. Orth, J. F. Hulvat, S. E. Kiehna, M. Barbeek, A. Rasic, S. I. Stupp and C. J. Kirkpatrick, Biomaterials, 2009, 30, 6202-6212.

51 L. W. Chow, R. Bitton, M. J. Webber, D. Carvajal, K. R. Shull, A. K. Sharma and S. I. Stupp, Biomaterials, 2011, 32, 15741582.

52 J. Kisiday, M. Jin, B. Kurz, H. Hung, C. Semino, S. Zhang and A. J. Grodzinsky, Proc. Natl. Acad. Sci. U. S. A., 2002, 99, 999610001; R. E. Miller, P. W. Kopesky and A. J. Grodzinsky, Clin. Orthop. Relat. Res., 2011, 469, 2716-2724.

53 R. E. Miller, A. J. Grodzinsky, E. J. Vanderploeg, C. Lee, D. J. Ferris, M. F. Barrett, J. D. Kisiday and D. D. Frisbie, Osteoarthritis Cartilage, 2010, 18, 1608-1619.

54 R. N. Shah, N. A. Shah, M. M. Del Rosario Lim, C. Hsieha, G. Nuber and S. I. Stupp, Proc. Natl. Acad. Sci. U. S. A., 2010, 107, 3293-3298.

55 H. Misawa, N. Kobayashi, A. Soto-Gutierrez, Y. Chen, A. Yoshida, J. D. Rivas-Carrillo, N. Navarro-Alvarez, K. Tanaka, A. Miki, J. Takei, T. Ueda, M. Tanaka, H. Endo, N. Tanaka and T. Ozaki, Cell Transplant., 2006, 15, 903-910. 56 H. Nakahara, H. Misawa, A. Yoshida, T. Hayashi, M. Tanaka, T. Furumatsu, N. Tanaka, N. Kobayashi and T. Ozaki, Cell Transplant., 2010, 19, 791-797.

57 T. Kahgo, Y. Yamada, K. Ito, A. Yajima, R. Yoshimi, K. Okabe, S. Baba and M. Ueda, Int. J. Periodontics Restorative Dent., 2011, 31, 9-16.

58 H. Pan, S. Hao, Q. Zheng, J. Li, J. Zheng, Z. Hu, S. Yang, X. Guo and Q. Yang, Mater. Sci. Eng., C, 2013, 33, 3336-3345. 59 T. Hou, Z. Li, F. Luo, Z. Xie, X. Wu, J. Xing, S. Dong and J. Xu, Biomaterials, 2014, 35, 5689-5699; Z. Li, T. Hou, F. Luo, Z. Chang, X. Wu, J. Xing, M. Deng and J. Xu, Int Orthop., 2014, DOI: 10.1007/s00264-014-2388-9.

60 J. E. Kim, S. M. Lee, S. H. Kim, P. Tatman, A. O. Gee, D. H. Kim, K. E. Lee, Y. Jung and S. J. Kim, Int. J. Nanomed., 2014, 9, 141-157. 
61 P. A. Brunton, R. P. W. Davies, J. L. Burke, A. Smith, A. Aggeli, S. J. Brookes and J. Kirkham, Br. Dent. J., 2013, 215, 1-6.

62 A. Mata, Y. Geng, K. J. Henrikson, C. Aparicio, S. R. Stock, R. L. Satcher and S. I. Stupp, Biomaterials, 2010, 31, 60046012; J. D. Hartgerink, E. Beniash and S. I. Stupp, Science, 2001, 294, 1684-1687.

63 T. D. Sargeant, M. O. Gulerb, S. M. Oppenheimera, A. Mata, R. L. Satcher, D. C. Dunanda and S. I. Stupp, Biomaterials, 2008, 29, 161-171.

64 S. S. Lee, B. J. Huang, S. R. Kaltz, S. Sur, C. J. Newcomb, S. R. Stock, R. N. Shah and S. I. Stupp, Biomaterials, 2013, 34, 452-459.
65 L. W. Chow, L. Wang, D. B. Kaufman and S. I. Stupp, Biomaterials, 2010, 31, 6154-6161.

66 N. Akiyama, T. Y. Fukuda, H. Takahashi and T. Koji, Int. J. Nanomed., 2013, 8, 2629-2640.

67 G. Uzunalli, Z. Soran, T. S. Erkal, Y. S. Dagdas, E. Dinc, A. M. Hondur, K. Bilgihan, B. Aydin, M. O. Guler and A. B. Tekinay, Acta Biomater., 2014, 10, 1156-1166.

68 M. Mazza, A. Patel, R. Pons, C. Bussy and K. Kostarelos, Faraday Discuss., 2013, 166, 181-194.

69 Y. Kondo, T. Nagasaka, S. Kobayashi, N. Kobashi and T. Fujiwara, Hepato-Gastroenterology, 2014, 130, 349-353. 